Felizmente,

todo pasó como esos trajes clínicos

de un alegre hospital desconocido.

La esponja de su boca

cayó desvanecida por el aire salino

y un murciélago blanco atravesó el verano

cimbrando de alegría

los columpios del sol.

\title{
Vicente Gerbasi
}

TIRANO DE SOMBRA Y FUEGO

\section{X I I}

Caballos,

caballos de la noche van corriendo

por las hierbas delgadas de los astros,

de horizonte a horizonte, donde el hombre

guarda la soledad en las guitarras.

Caballos,

caballos del misterio van corriendo

con lumbres en los lomos, bajo el trueno

que estremece las aguas estancadas

y los juncos dispersos del relámpago.

Caballos,

caballos de la furia van corricndo

por un azul desierto de palmeras

hechas de altos reflejos en el cielo

$y$ de rumor del viento que las mueve.

Caballos,

caballos de los mucrtos van corriendo

entre gritos que salen de los ríos,

de las aguas que lloran en la orilla

lenta de las luciérnagas del tiempo. 
Caballos, caballos con sonido de tu muerte van corriendo.

Pedro Lastra

\section{TRASLADO A LA MANANA}

Lejos resuena un pito de tren

y desde el árbol los pájaros emprenden su vuelo; no es nada,

sólo que los píjaros nos roban el cielo desde la frente y pensamos en los que viajan, en las vueltas que damos nosotros mismos alrededor de la habitación y en algunas palabras que me agradaria repetirte, algunas cosas, sobre todo, que me desvelan tanto como el ruido de la ciudad, algunas cosas inconclusas.

Pero tú estás en la pieza vecina y preparas las ropas del día más próximo, algo con que esperarlo contésmente a pesar nuestro, porque tú y yo nos sentimos bien en este espacio destinado al sábado inicial de primavera y resulta molesto ese traslado forzoso a la mañana, tú y yo a la mañana, sin tener tiempo para escribir unas líneas de despedida, para mirar el polvo que cae sobre el espejo tras los últimos pasos y detenernos a velar a los muertos. 